\title{
Continuous Twin Screw Rheo-Extrusion of an AZ91D Magnesium Alloy
}

\begin{abstract}
M. XIA, Y. HUANG, Z. CASSINATH, and Z. FAN
The twin screw rheo-extrusion (TSRE) is designed to take advantage of the nondendritc microstructure and thixotropic characterization of semisolid-metal slurries and produce simple metal profiles directly from melts. The extrusion equipment consists of a rotor-stator high shear slurry maker, a twin screw extruder, and a die assembly. The process is continuous and has a potential for significantly saving energy, manufacturing cost, and enhancing efficiency. The present investigation was carried out to study the process performance for processing rods of an AZ91D magnesium alloy and the microstructure evolution during processing. The semisolid slurry prepared by the process was characterized by uniformly distributed nondendritic granular primary phase particles. AZ91D rods with uniform and fine microstructures and moderate mechanical properties were produced. For the given slurry making parameters, decreasing extrusion temperature was found to improve microstructures and properties. The mechanisms of particle granulation and refinement and the effect of processing parameters on process performance and thermal management are discussed.
\end{abstract}

DOI: $10.1007 / \mathrm{s} 11661-012-1201-\mathrm{x}$

(C) The Minerals, Metals \& Materials Society and ASM International 2012

\section{INTRODUCTION}

SINCE the discovery of the semisolid metal (SSM) phenomenon in the early 1970 s by the Flemings Group at MIT ${ }^{[1]}$ SSM processing has been increasingly used for metal forming. ${ }^{[2-4]}$ SSM forming, being conducted at temperatures between the liquidus and solidus of the material, has advantages over solid-state forming such as significantly reduced forming force, unlimited formability, and shortened manufacturing route, and advantages over conventional die casting, including lowered operating temperatures, laminar flow during mold filling, and reduced solidification shrinkage. ${ }^{[2,5]}$ SSM forming offers the potential for significant savings in cost, energy, and resources for metal production.

However, the envisaged benefits such as effective process control, microstructure engineering, and property enhancement have yet to be fully realized for the existing SSM processing technologies. Actually, there is an increased complexity in the process control for most of the SSM forming processes, particularly for those via a thixo-route, ${ }^{[6]}$ in which preprocessed alloys of nondendritic microstructures formed by electromagnetic stirring ${ }^{[7,8]}$ or plastic deformation and recrystallization $^{[9-11]}$ are heated to the semisolid region prior to forming. The preprocessed nondendritic alloys are expensive and normally suffer heterogeneous heating before forming. There are several rheo-SSM forming processes, in which semisolid slurry is made directly

M. XIA, Senior Research Fellow, Y. HUANG, Lecturer, Z. FAN, Professor, BCAST, and Z. CASSINATH, Postdoctoral Student, are with Brunel University, Uxbridge, Middlesex, UB8 3PH, United Kingdom. Contact «email: yan.huang@brunel.ac.uk

Manuscript submitted November 22, 2011.

Article published online July 19, 2012 from melts, such as gas-induced semisolid rheo-extrusion, ${ }^{[12]}$ cooling tube feeding semisolid rheo-extrusion, ${ }^{[13]}$ single screw rheo-molding, ${ }^{[14]}$ and twin screw rheo-molding. ${ }^{[15]}$ These processes adopt simplified slurry making procedures via a rheo-route and are potentially of enhanced efficiency. However, they are all of batch nature with limited commercial forthcoming.

In order to take full advantage of SSM forming technology, it is important to adopt a continuous process via a rheo-route. A continuous process offers enhanced efficiency, productivity, and savings of cost and materials, while a rheo-route represents the simplest route for slurry making. Their combination is thus arguably the best technical approach in terms of commercial competitiveness. Therefore, a twin screw rheo-extrusion (TSRE) process was recently developed at Brunel University as a continuous SSM process for producing wires, rods, and simple profiles of metals and alloys directly from melts. A direct aim of this development was to provide an alternative route for the conventional solid-state extrusion, in which billet feedstock undergoes multiple processing procedures before extrusion such as casting, heat treatment, machining, lubricating, reheating, etc. This TSRE process can be particularly useful for materials with limited formability for conventional forming such as magnesium and its alloys. The present article reports a feasibility study of the TSRE process for the continuous production of a commercial AZ91D magnesium alloy with focus on process verification and microstructure control. The AZ91D was chosen because it has certain wroughtability in addition to its excellent castability, is easier to process than purer alloys, and has been widely studied in semisolid processing. ${ }^{[16-22]}$ Besides, there is a niche market for AZ91 magnesium alloy welding rods, which are difficult to produce using conventional processes. 


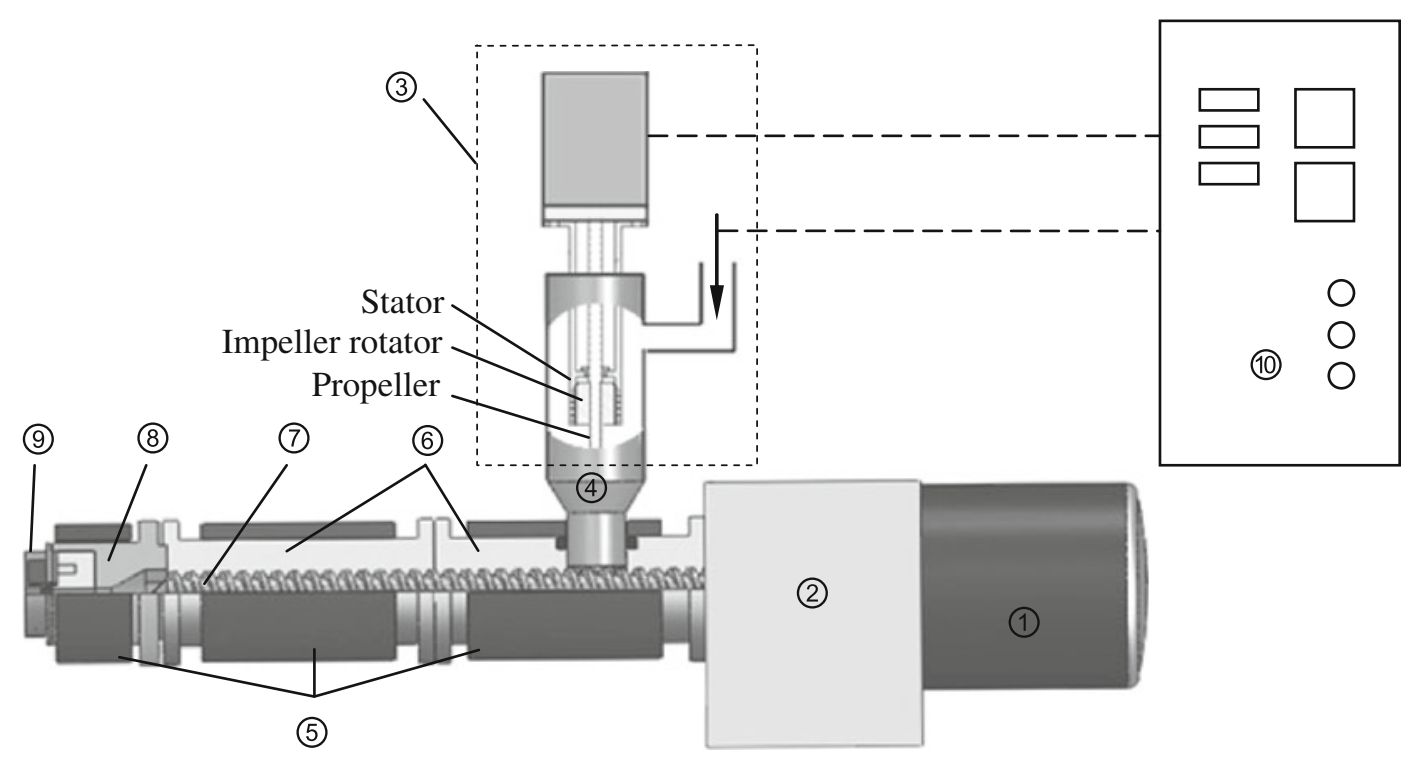

Fig. 1-Schematic illustrations of the TSRE process including the main parts: 1-motor, 2-gear box, 3-rotor-stator high shear slurry maker, 4 -funnel, 5-heaters, 6- barrel, 7-screws, 8 - die system, 9-water spray cooler, and 10 - central control panel.

\section{TSRE PROCESS}

\section{A. TSRE Process}

The novel TSRE process is schematically shown in Figure 1. It consists of a slurry making and feeding unit, a twin screw extruder, a die assembly, and a central control system. The twin screw extruder is the core of the process and has a pair of intermeshed counter rotating mirror-identical screws tightly fitted in a closet multisection barrel. The screws have a specially designed profile that can generate high shear rate and high intensity of turbulence to the slurry to be processed and at the same time apply a forward displacement pumping action. In the process, liquid metal is first transformed into slurry of predetermined solid fraction in the high shear slurry maker and fed into the extruder via a guiding funnel. The slurry in the extruder is further sheared and propelled by the rotating screws toward the die assembly and extruded out of the die. The entire process is continuous.

\section{B. Slurry Making and Feeding}

Slurry making directly from the melt is a technical challenge for continuous rheo-SSM processing. Current slurry making techniques are largely developed for SSM mold casting/forging and are difficult to use for a continuous process. In the TSRE process, the online slurry maker (Figure 1) uses a rotor-stator device, which can apply an ultrahigh shear rate to the melt at a controlled cooling rate and can process semisolid slurry of the required solid fraction at a sufficiently high speed for the continuous processing of profiles in a range of dimensions and at a high extrusion speed. The slurry maker consists of a rotor with an impeller and a propeller driven by the same motor, an open cylinder stator with narrow apertures at its bottom section, and a melt container equipped with thermal control elements. In the slurry making process, the impeller rotates at a high speed between 5000 and $15,000 \mathrm{rpm}$, sucking the melt/slurry into the stator, applying high shear to the melt, and forcing the melt/ slurry through the narrow apertures. The material flow is characterized as a smooth and continuous convection. The propeller at the bottom of the device, being extended down to the guiding funnel, is used to assist feeding. The feeding speed is determined by the extrusion speed $(V)$, and the required slurry making rate $\left(V_{s}\right)$ is related to $V$ by

$$
V_{s}=V\left(\frac{\phi}{D_{s}}\right)^{2}
$$

where $\phi$ is the diameter of the extruded rod and $D_{s}$ is the equivalent diameter of the cylinder contrainer of the slurry maker. The height of the melt level in the slurry container $(H)$ is determined by the product of $V_{s}$ and the time needed for obtaining the required solid fraction $\left(t_{s}\right)$ at a given cooling rate as $H=V_{s} t_{s}$.

\section{Transport and Forming}

The transport of the online prepared slurry is governed by the geometry of the screws and barrel along with the rotation speed and viscosity of the slurry. ${ }^{[15]}$ The rotation screws drive the slurry forward and apply further shearing and thinning effect. This shear also ensures that the nondendritic structures in the slurry are maintained and that the temperature and chemical compositions are uniform. By the rotation of the screws, a positive displacement effect is created and the slurry is transported along the axis of the barrel to the die assembly, where it can be extruded. The time for the slurry to be transported from the feeding point to the die assembly $\left(t_{T}\right)$ is determined by the extrusion rate and the extruder geometry as 


$$
t_{T}=\frac{4 A L}{\pi \phi^{2} V}
$$

where $A$ is the equivalent gap area of the twin screws cross section that carries the slurry and $L$ the barrel length of the extruder. The die assembly has a length of straight outlet orifice, which controls the shape and dimensions of the cross section of the extruded profiles. The inner profile of the barrel is converged toward the die assembly, which has an open chamber in line with the barrel inner profile. The pressure on the slurry is built to its highest in the die chamber, and extrusion takes place when the slurry is forced out of the die through a narrow outlet. A water cooling system is employed at the exit of the die to fully solidify the extruded rod, which can thus be readily collected with a trough or a coiler.

\section{Advantageous Features of the TSRE Process}

TSRE provides a one-step melt-to-product process and has the potential to reduce manufacturing costs by eliminating the multi procedures for billet preparation and by using lightweight processing equipment compared with the conventional solid-state extrusion; further, this process saves materials because it can be kept in-house and the materials are $\sim 100$ pct recyclable. In addition, the shortened manufacturing route and continuous nature of the process can significantly enhance efficiency. The TSRE process as an enabling technology eliminates the artificial boundaries between shape casting and wrought alloy processing by directly forming wrought products.

\section{EXPERIMENTS}

\section{A. Material and Slurry Making Conditions}

A commercial AZ91D magnesium alloy with nominal compositions of $\mathrm{Mg}-8.6 \mathrm{Al}-0.67 \mathrm{Zn}-0.22 \mathrm{Mn}$ (wt pet), supplied by Magnesium Elektron Ltd. (Manchester, United), was used in this investigation. The alloy was melted in a steel crucible at $953 \mathrm{~K}\left(680{ }^{\circ} \mathrm{C}\right)$ and held at $923 \mathrm{~K}\left(650^{\circ} \mathrm{C}\right)$ for half an hour. The melt was further cooled to $873 \mathrm{~K}\left(600{ }^{\circ} \mathrm{C}\right)$, just above the liquidus point $\left(871 \mathrm{~K}\left(598{ }^{\circ} \mathrm{C}\right)\right)$, before being poured into the slurry maker. The melt was cooled at an average rate of $\sim 5^{\circ} \mathrm{C} /$ min in the slurry maker and sheared at a rotation speed of $3000 \mathrm{rpm}$. The height of the slurry level was kept at about $220 \mathrm{~mm}$ in the container of $100-\mathrm{mm}$ diameter, giving about 2 minutes processing time before being fed into the barrel at a temperature of $863 \mathrm{~K}\left(590{ }^{\circ} \mathrm{C}\right)$. A protective atmosphere of $\mathrm{N}_{2}+0.4 \mathrm{vol}$ pct $\mathrm{SF}_{6}$ was used in both melting and slurry making operations.

\section{B. Twin Screw Extrusion}

A die assembly made from steel and graphite with a $10 \mathrm{~mm}$ i.d. straight outlet was used with an external water cooling system. The slurry making and feeding

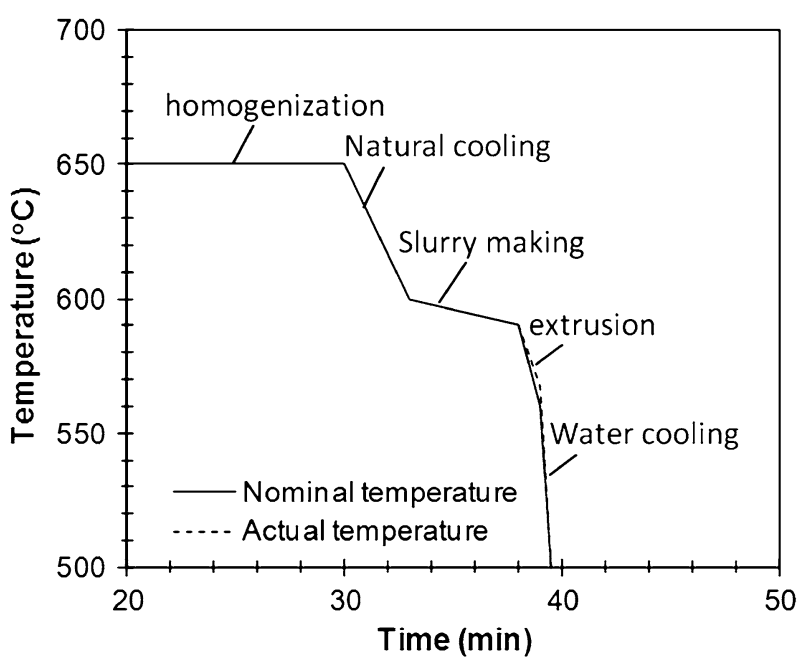

Fig. 2-Typical thermal scheme for the processing of an AZ91D magnesium alloy: melt homogenization at $923 \mathrm{~K}\left(650^{\circ} \mathrm{C}\right)$ for $30 \mathrm{~min}$ and natural cooling to $873 \mathrm{~K}\left(600^{\circ} \mathrm{C}\right)$; then shearing and cooling in the slurry maker for $\sim 2 \min$ to $863 \mathrm{~K}\left(590^{\circ} \mathrm{C}\right)$ before feeding to the extruder at a lower temperature, traveling through the barrel for about $15 \mathrm{~s}$ before extrusion and water chilling.

unit, barrel, and die assembly were all bracketed by wellcontrolled band heaters and the temperature variation was controlled within $\pm 1{ }^{\circ} \mathrm{C}$. The twin screw extruder, including the die assembly, was soaked at the extrusion temperature $\left(T_{e}\right)$ ranging from $818 \mathrm{~K}$ to $863 \mathrm{~K}\left(545^{\circ} \mathrm{C}\right.$ to $590{ }^{\circ} \mathrm{C}$ ) for an hour before extrusion. The slurry feeding temperature $\left(T_{f}\right)$ was fixed at $863 \mathrm{~K}\left(590{ }^{\circ} \mathrm{C}\right)$, which was higher than the extrusion temperatures for all experiments, allowing an increase in solid fraction to occur during extrusion. Although various twin screw rotation rates were tested, most extrusion experiments were conducted at $150 \mathrm{rpm}$, resulting in an extrusion speed of $\sim 10 \mathrm{~m} / \mathrm{min}$. Again, a protective atmosphere of $\mathrm{N}_{2}+0.4$ vol pct $\mathrm{SF}_{6}$ was used during extrusion. Figure 2 shows a typical thermal scheme that the material underwent during the process.

\section{Microstructure Examination and Mechanical Testing}

The extruded samples were examined using optical microscopy to reveal the microstructural features as a function of processing parameters. Unless stated, the surfaces examined were sectioned through the longitudinal central plane of the extruded rods. Samples of water-quenched slurries before extrusion were also examined in order to understand the effect of the slurry preparation conditions on microstructural development. The samples were prepared following standard metallographic procedures and etched with 5 pct Nital solution for examining quenched semisolid structures and with picric-ethanol solution $\left(4.2 \mathrm{~g}\right.$ picric acid, $10 \mathrm{~mL} \mathrm{H}_{2} \mathrm{O}$, and $70 \mathrm{~mL}$ ethanol) for color etching for observing deformation structures and measuring grain size. The metallographic examinations were performed on a Zeiss optical microscope equipped with an image analysis system. Grain size measurement was carried out following ASTM standard E112-96. Tensile 
specimens were machined from the extruded AZ91D rods into standard dog-bone tensile bars of $6.5-\mathrm{mm}$ diameter in a gage length of $25 \mathrm{~mm}$. The tensile test was conducted on an INSTRON* 5569 universal test

*INSTRON is a trademark of Instron, Canton, MA.

machine at room temperature and at a strain rate $0.66 \times 10^{-3} / \mathrm{s}$.

\section{EXPERIMENTAL RESULTS}

\section{A. General Performance}

Under the selected range of temperature, speed, and cooling rate, the continuous semisolid extrusion of the AZ91D alloy by the TSRE process was successfully carried out. An essential requirement for the successful operation of the extrusion process is that the material extruded out of the die holds its shape in air or under water cooling. This requires a sufficient fraction of solid particles in the slurry so that a continuous solid skeleton throughout the volume of the material is formed. Preliminary trials showed that slurry feeding at temperatures below $863 \mathrm{~K}\left(590^{\circ} \mathrm{C}\right)$ was not smooth due to increased viscosity, and $863 \mathrm{~K}\left(590^{\circ} \mathrm{C}\right)$ was then chosen as the feeding temperature for all extrusion experiments. However, the solid fraction in the slurry at this temperature was not high enough to hold its shape after extrusion.

Therefore, extrusion temperatures lower than this feeding temperature were employed, as shown in Figure 2, to allow further solidification, giving rise to an increase in solid fraction during extrusion. Figure 3 shows typical samples processed in a range of extrusion temperatures. The extruded rod held its shape upon water cooling when the extrusion temperature was below $853 \mathrm{~K}\left(580{ }^{\circ} \mathrm{C}\right)$, although severe surface voids and cracks were observed at extrusion temperatures between $843 \mathrm{~K}$ and $853 \mathrm{~K} \quad\left(570{ }^{\circ} \mathrm{C}\right.$ and $\left.580{ }^{\circ} \mathrm{C}\right)$ (Figures 3(a) and (b)). At $838 \mathrm{~K}\left(565^{\circ} \mathrm{C}\right)$, the extruded rods exhibited a good shape and reasonably good surface finish. The possible lowest extrusion temperature was $818 \mathrm{~K}\left(545^{\circ} \mathrm{C}\right)$ due to limited extrusion force.

\section{B. Microstructures of Slurry}

Figure 4 shows the microstructures of the waterquenched samples of slurry prepared at different temperatures. The samples were of 0.25 to $0.5 \mathrm{~cm}^{3}$ in volume, quenched for less than half a second, and cut through the volume center at random orientation. It can be seen from the figure that the majority of the solid particles are essentially granular at all temperatures, although some small particles are dendritic or rosettelike, probably due to limited solidification during quenching. Both the solid fraction and average particle size increased as the slurry making temperature decreased, while the particle morphology seemed to be independent of temperature. Overall, the formation of the globular semisolid structure showed similar nature

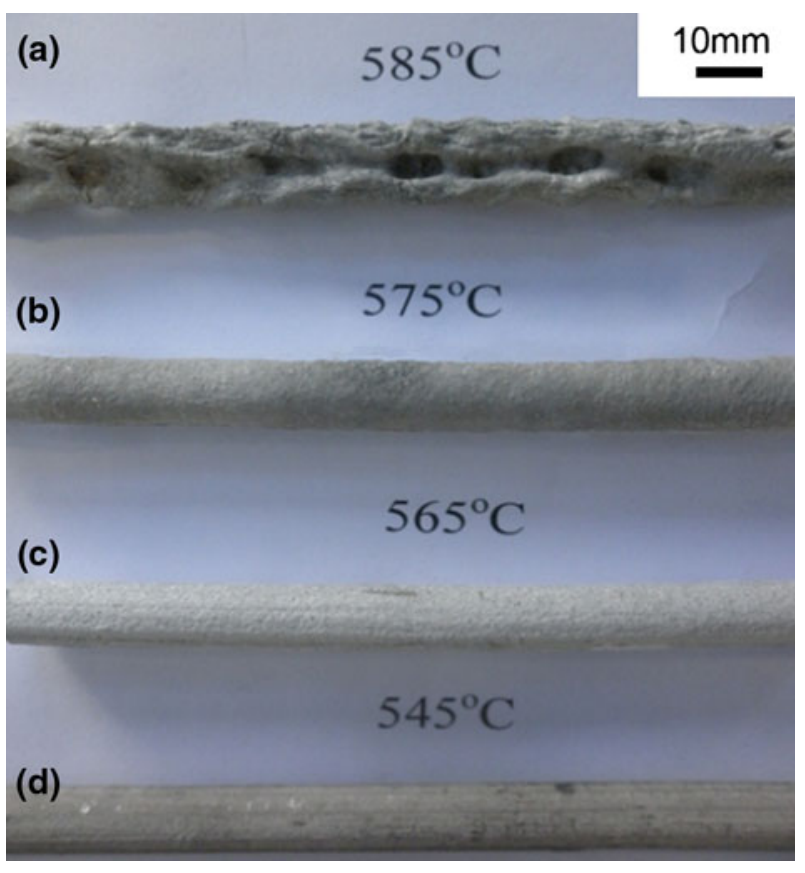

Fig. 3-Samples of extruded rods at a fixed feeding temperature of $863 \mathrm{~K}\left(590{ }^{\circ} \mathrm{C}\right)$ and various extrusion temperatures: (a) $858 \mathrm{~K}$ $\left(585^{\circ} \mathrm{C}\right)$, (b) $575^{\circ} \mathrm{C}$, (c) $838 \mathrm{~K}\left(565^{\circ} \mathrm{C}\right)$, and (d) $818 \mathrm{~K}\left(545^{\circ} \mathrm{C}\right)$, showing the improvement of the shape and surface finish of extruded AZ91D rods with decreasing extrusion temperature.

to the microstructure evolution in normal rheo-forming processes, ${ }^{[5,23]}$ suggesting that the applied convection and high rate shear was sufficient to produce the slurry of granular particles required by the process.

Characteristic parameters of solid particles in slurry as a function of temperature were determined from microstructure analysis. The shape factor $(F)$ was estimated by the relation $F=\pi S / P^{2}$, where $S$ and $P$ are the average area and perimeter of particles, respectively. $F$ equals a unit for a perfect spherical structure. For the quenched slurries, $F$ was measured to be about 0.6 at $870 \mathrm{~K}\left(597{ }^{\circ} \mathrm{C}\right)$ and increased steadily with decreasing temperature, reaching a value of 0.73 at $853 \mathrm{~K}\left(580{ }^{\circ} \mathrm{C}\right)$. The contiguity factor $(C)$ was estimated using the relation $C=2 N_{\alpha \alpha} /$ $\left(2 N_{\alpha \alpha}+N_{\alpha \beta}\right)$, where $N_{\alpha \alpha}$ is the number of intersections per unit length of test lines between primary $\alpha$-phase particles, which are supposed to be the solid particles in the slurry, and $N_{\alpha \beta}$ is the number of intersections per unit length of test lines between the primary $\alpha$-phase particles and the secondarily solidified phases, which include all phases that solidified after quenching. The value of $C$ was found in the range of 0.35 to 0.45 independent of temperature, indicating that there was only limited particle agglomeration.

The particle size $(D)$ was measured by following the ASTM Standard E112-96, and the particle density $\left(N_{s}\right)$ was estimated by counting particles in a number of randomly selected areas of certain dimensions. Figures 5(a) and (b) show the size and density of primary phase particles as a function of slurry making temperature, including the data obtained from the extruded samples. As shown in Figure 5(b), the particle density increases almost linearly with decreasing slurry making 

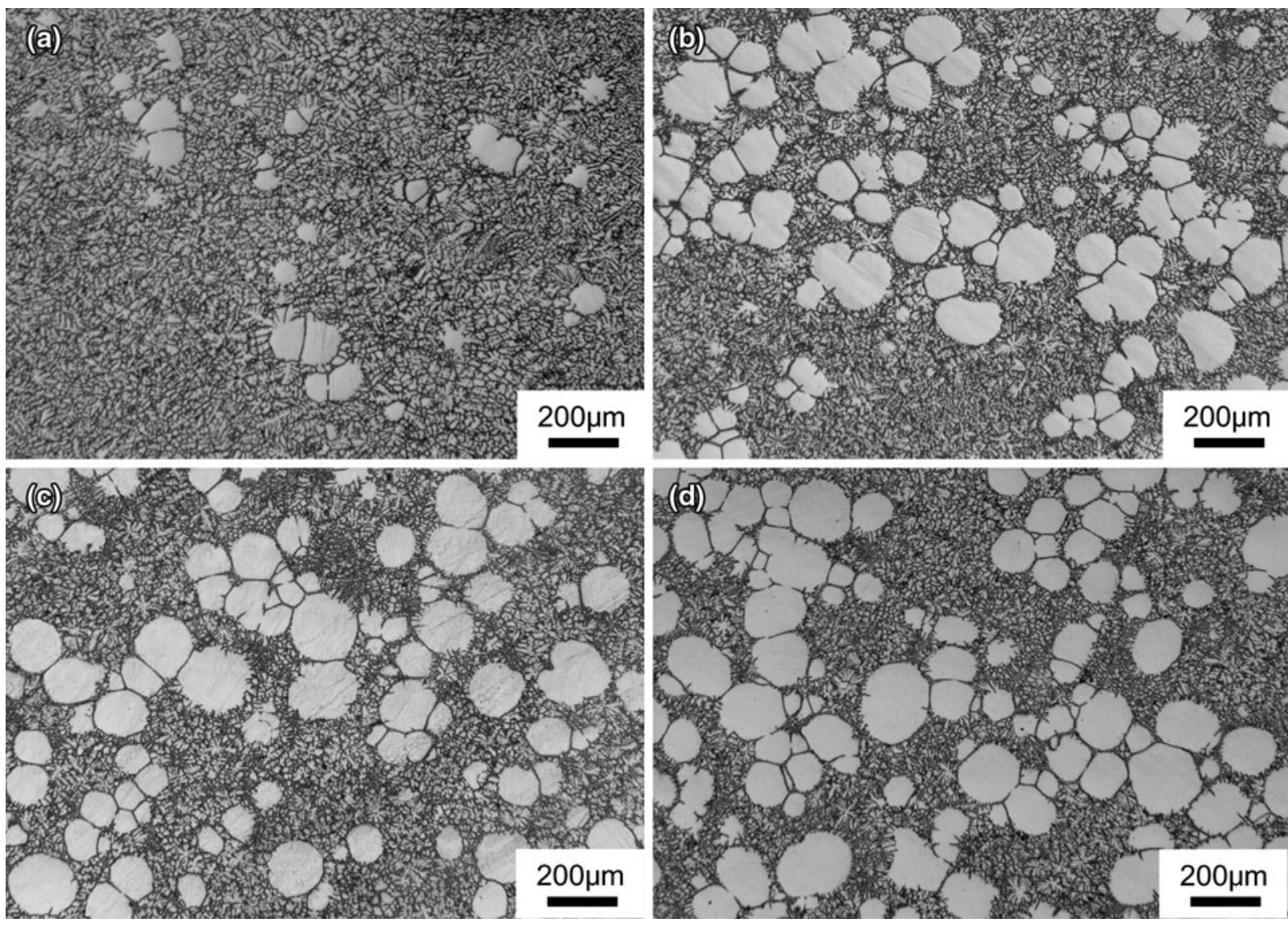

Fig. 4 - Optical micrographs showing microstructures of the AZ91D slurry prepared at a range of temperatures: $(a) 870 \mathrm{~K}\left(597{ }^{\circ} \mathrm{C}\right),(b) 866 \mathrm{~K}$ $\left(593{ }^{\circ} \mathrm{C}\right),(c) 863 \mathrm{~K}\left(590^{\circ} \mathrm{C}\right)$, and $(d) 858 \mathrm{~K}\left(585^{\circ} \mathrm{C}\right)$. The microstructures were retained by water quenching at the corresponding temperatures.

temperature and extrusion temperature. On the other hand, the particle size underwent a quick increase from $870 \mathrm{~K}$ to $866 \mathrm{~K}\left(597{ }^{\circ} \mathrm{C}\right.$ to $\left.593^{\circ} \mathrm{C}\right)$ and then stayed at a roughly constant level with decreasing temperature. Because decreasing slurry making temperature actually increases the time for slurry processing and consequently for the solidified particles to grow, the constant particle size suggests that the high shear treatment prevented the solidified particles from extensive growth, although the mechanisms are not clear. The volume fraction of solid particles $\left(F_{s}\right)$ in the slurry was calculated from the measured particle size $(D)$ and density $\left(N_{s}\right)$ by

$$
F_{s}=\frac{\pi D^{2}}{6} N_{s}
$$

assuming a random particle distribution. The calculated results are given in Figure 5(c) compared with the theoretical predictions from the Scheil equation for equilibrium transformation (taking the partition coefficient of the alloy as 0.36). As shown in the figure, the calculated particle volume fraction is in good agreement with the theoretical predications, confirming the validity of particle size and density measurements.

\section{Microstructures of Extruded Rods}

Figure 6 shows typical microstructures extruded at $833 \mathrm{~K}\left(560{ }^{\circ} \mathrm{C}\right)$ and the grain size variation over the cross section (Figure 6(a)) and along the longitudinal central plane over a length of $3.5 \mathrm{~m}$ from the starting end (Figures 6(b) through (d)), and it may be seen that microstructures are uniform in both planes. The extruded microstructures were mainly comprised of primary $\alpha$-phase particles embedded in the networks of secondarily solidified dendritic networks. The primary particles were substantially globular with an average shape factor of 0.87 over the entire range of tested extrusion temperatures. Temperature had a strong impact on the extrusion microstructures, including the size and morphology of primary $\alpha$-phase particles and secondary phases, and on plastic deformation behavior as well. Figure 7 shows microstructures extruded at different temperatures. It can be seen that the primary phase grain size decreases with decreasing temperature, while the overall grain shape and uniformity remain unchanged. The average primary phase grain size as a function of extrusion temperature was measured, and the results are shown in Figure 5(a). The primary particle size extruded at $858 \mathrm{~K}\left(585^{\circ} \mathrm{C}\right)$ is clearly smaller than the particle size in the slurry quenched at the same temperature, suggesting that the extrusion had a refinement effect. The primary particle size reduced gradually as the extrusion temperature decreased, and there seemed to be a turning point at $833 \mathrm{~K}\left(560^{\circ} \mathrm{C}\right)$, below which the particle size reduced more quickly with decreasing extrusion temperature. At $818 \mathrm{~K}\left(545^{\circ} \mathrm{C}\right)$, 


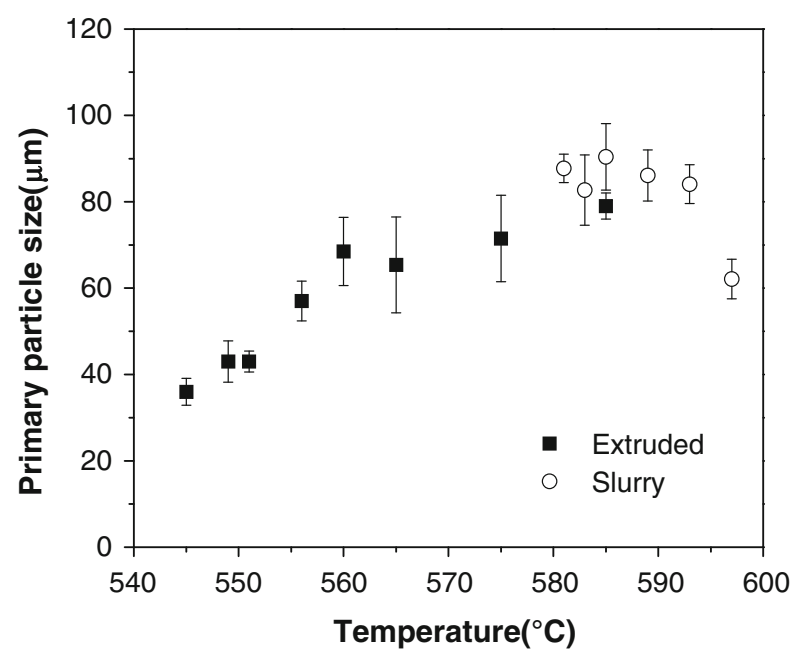

(a)

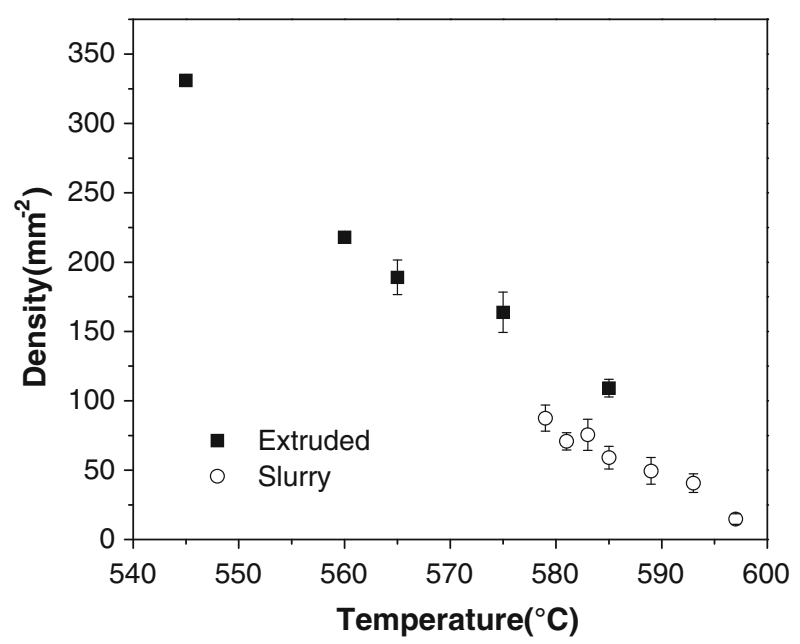

(b)

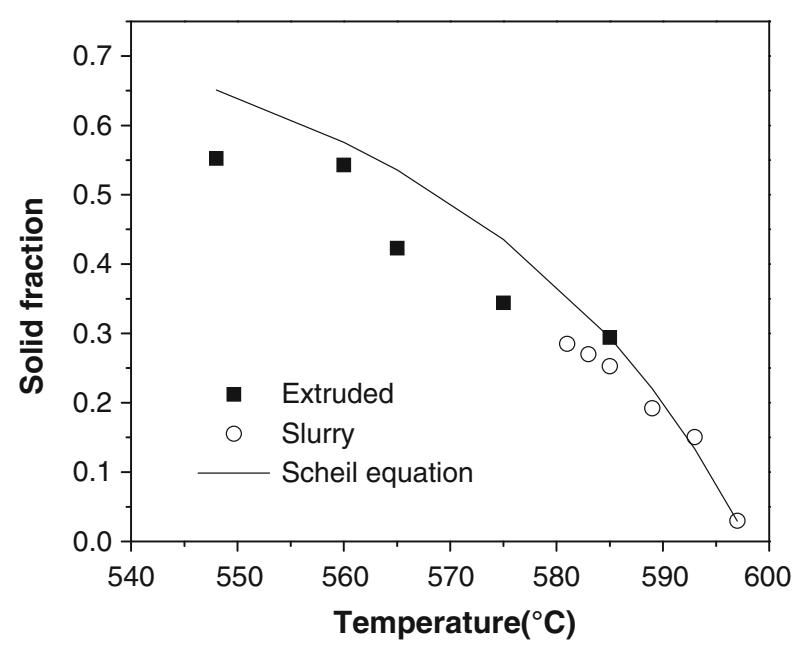

(c)

Fig. 5-Microstructural parameters of the AZ91D slurry as a function of temperature: (a) primary particle size, (b) density, and (c) solid fraction of primary particles in comparison with predictions by the Scheil equation; the corresponding data of primary particle size, density, and volume fraction for the as-extruded samples are included. The error bars show the standard deviation of the data. an average primary particle size of $35 \mu \mathrm{m}$ was obtained, which is considerably smaller than the reported values for microstructures obtained by semisolid processing in the same material. ${ }^{[17-21]}$

At relatively lower extrusion temperatures, plastic deformation took place and is considered to contribute to the particle size decrease. Although most of the deformation features are expected to be removed by dynamic recovery at semisolid temperatures, twins and dislocation cells were observed for samples extruded at relatively low temperatures. As shown in Figure 8, the main deformation features are twins at $833 \mathrm{~K}\left(560{ }^{\circ} \mathrm{C}\right)$, while dislocation cells/microbands (shown as DCs/MBs in the figure) are dominant at $818 \mathrm{~K}\left(545^{\circ} \mathrm{C}\right)$, in addition to twins. No shear bands cutting through more than one primary particle were observed, indicating that plastic deformation only occurred in response to the local stress state. Plastic deformation by twinning and orientation splitting, due to local restrictions to dislocation slip, introduces new boundaries and may explain the relatively faster decrease of grain size at low extrusion temperatures. However, the overall plastic deformation should be limited, because no significant changes in particle shape were observed in response to the plastic deformation. The intermetallic networks formed during secondary solidification became thinner and discontinuous as the extrusion temperature, accordingly the liquid fraction in the slurry, decreased. The optical micrographs in Figure 9 were obtained from slightly etched surfaces, showing the continuous intermetallic networks for a sample obtained at $853 \mathrm{~K}$ $\left(580^{\circ} \mathrm{C}\right)$ (Figure 9(a)), compared with the thin and broken intermetallics formed during extrusion at $818 \mathrm{~K}$ $\left(545^{\circ} \mathrm{C}\right)$ (Figure $\left.9(\mathrm{~b})\right)$.

\section{Mechanical Properties of Extruded Rods}

Figure 10 shows typical tensile stress-strain curves for specimens extruded at $833 \mathrm{~K}$ and $818 \mathrm{~K}\left(560{ }^{\circ} \mathrm{C}\right.$ and $545^{\circ} \mathrm{C}$ ), respectively. An average elongation of $5.7 \mathrm{pct}$ was obtained from specimens extruded at $818 \mathrm{~K}$ $\left(545^{\circ} \mathrm{C}\right)$ with an average yield strength of $87 \mathrm{MPa}$ and ultimate tensile strength of $186 \mathrm{MPa}$. The ductility decreased with increasing extrusion temperature to $\sim 1.8$ pct at $833 \mathrm{~K}\left(560^{\circ} \mathrm{C}\right)$, while the yield strength remained at the same level. The mechanical properties were lower compared with the solid-state processed values. The relatively large grain size, the existence of the networks of secondarily solidified dendritic primary phase, and the eutectic structures are considered to be the main reasons for the relatively low mechanical properties. However, the overall mechanical performance of the as-rheo-extruded rods was comparable with some of the thixomolding and rheo-die-casting products of the same material. ${ }^{[16,17,21]}$

\section{DISCUSSION}

The present experimental results confirmed that the continuous TSRE process is feasible for producing simple profiles of magnesium alloy with proper surface 


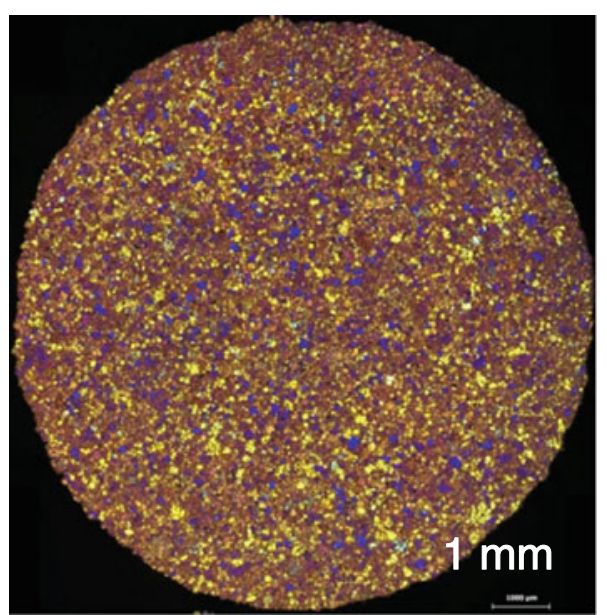

(a)

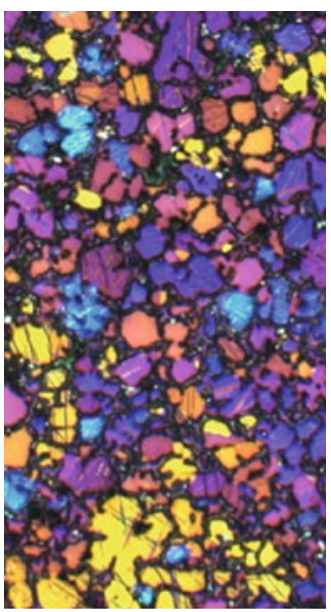

(b)

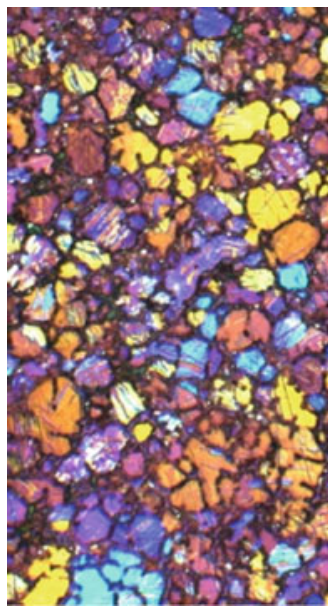

(c)

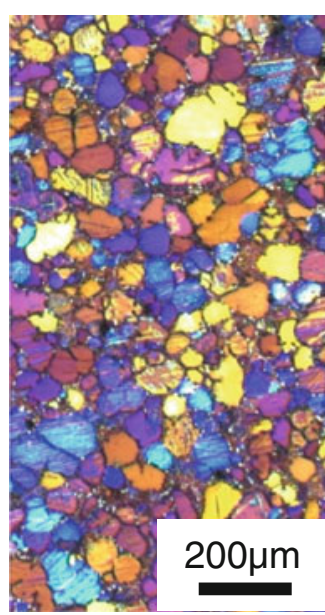

(d)

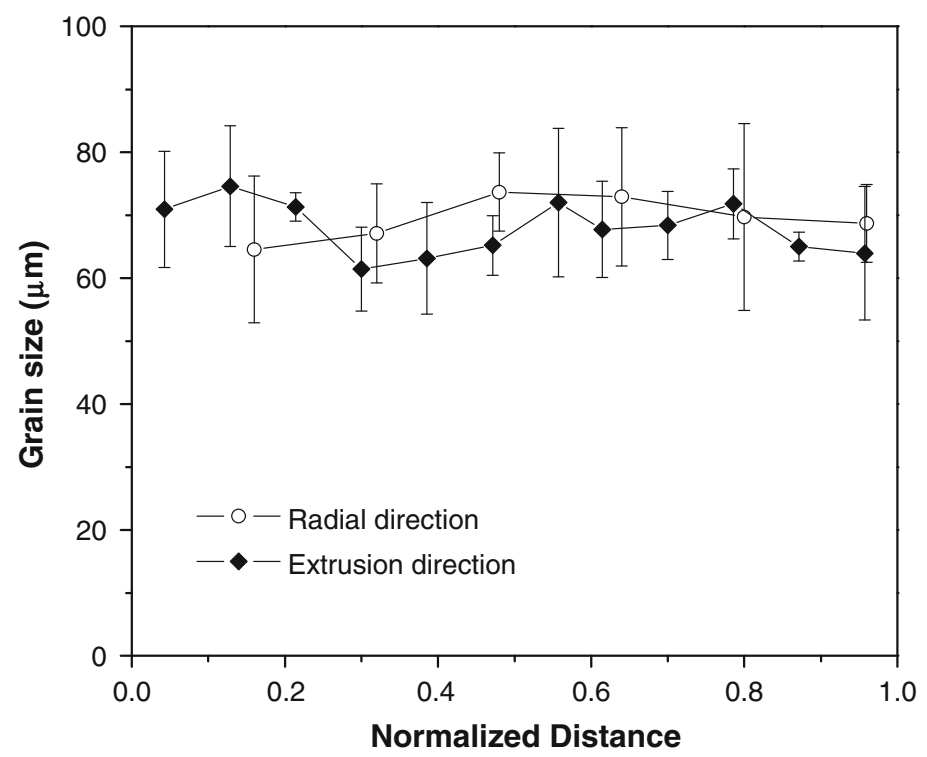

(e)

Fig. 6-Optical micrographs of the AZ91D rods extruded at $833 \mathrm{~K}\left(560{ }^{\circ} \mathrm{C}\right)$ and $10 \mathrm{~m} / \mathrm{min}$, showing the uniformity of microstructures on (a) short transverse cross section and $(b)$ through $(d)$ the longitudinal transverse section through the central plane from evenly separated positions over a length of $3.5 \mathrm{~m}$; (e) grain size as a function of normalized distance across the diameter of the rod and over the 3.5-m-long rod. The error bars show the standard deviation of the data.

quality and mechanical properties. The extrusion speed is substantially higher than a rheo-casting process, and the continuous nature of the process offers significant advantages over thixomolding and the conventional solid-state extrusion process. The process also exhibited a number of advantageous features in the control of microstructure.

\section{A. Development of Nondendritic Structures}

The formation of a nondendritic microstructure is critical for the TSRE process, because its high fluidity and rheological features allow the forming process to be performed continuously under a significantly reduced force. It is conventionally believed ${ }^{[5,24-30]}$ that nondendritic microstructures form under forced convection due to one or more of the following mechanisms: (1) dendritic arms remelting at their roots ${ }^{[25]}$ or liquid penetration through high-angle boundaries, ${ }^{[26]}(2)$ cellar growth and ripening effect, ${ }^{[27,28]}$ (3) dendrite arms bending due to thermal-solutal convection, ${ }^{[29]}$ or (4) dendrite fragmentation by mechanical force ${ }^{[5]}$ This conventional dendrite fragmentation theory provides a good explanation for solid particle multiplication but cannot explain why the detached fragments would grow into globules rather than dendrites. Recent experimental studies, ${ }^{[19,30]}$ supported by computer simulations, ${ }^{[31,32]}$ suggest that the turbulence of high shear helps transport the accumulated solute atoms away from the solid-liquid interface and stabilizes planar growth, restraining dendrite development. Hence, the nondendritic structure is believed to be essentially a direct result of spherical 

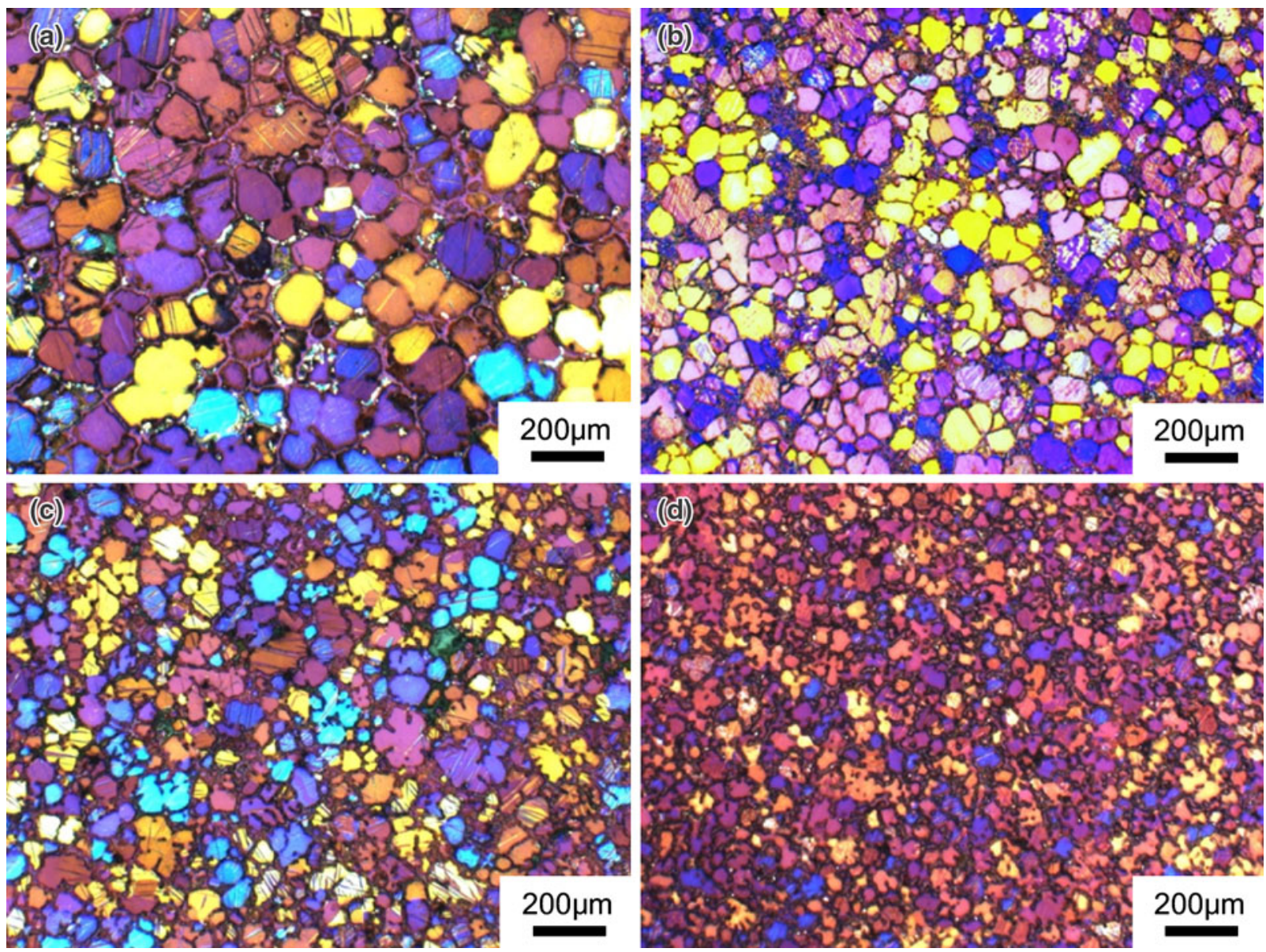

Fig. 7- Optical micrographs showing microstructures of the extruded AZ91D rods from the longitudinal transverse central plane as a function of extrusion temperature: $(a) 858 \mathrm{~K}\left(585^{\circ} \mathrm{C}\right)$, (b) $575^{\circ} \mathrm{C},(c) 833 \mathrm{~K}\left(560{ }^{\circ} \mathrm{C}\right)$, and $(d) 818 \mathrm{~K}\left(545^{\circ} \mathrm{C}\right)$.

growth under the forced convection. In the present study, the microstructures of slurry prepared over the entire range of temperature were substantially comprised of nondendritic primary particles (Figure 4), seemingly due to spherical growth. The particle density increase in the early stage of slurry making (Figure 5(b)) may well be explained by the effect of nucleation. The increased particle number and average particle size were the reasons for the increase of the solid fraction in the slurry, with a nearly ideal fit to the theoretical predictions (Figure 5(c)). It has been demonstrated that the forced convection by intensive shear promotes heterogeneous nucleation in magnesium alloys by generating uniformly distributed nucleation agents, uniform temperature, and composition fields. ${ }^{[33]}$ The enhanced heterogeneous nucleation by intensive shear is considered to be an important reason for the achievement of fine and uniform microstructures.

As shown in Figure 5, while particle density continued to increase, the average particle size quickly maximized at $866 \mathrm{~K}\left(593{ }^{\circ} \mathrm{C}\right)$ and then flatted against decreasing temperature. The continuous linear increase in particle density suggests that there were no significant changes in the nucleation-dominated mechanisms responsible for particle multiplication. It is then difficult to explain why the average particle size remained constant, which resulted in a negative deviation of the measured solid fraction from the theoretical predictions, as shown in Figure 5(b). In fact, the size of the largest particles in the slurry was almost constant, from $866 \mathrm{~K}$ to $858 \mathrm{~K}\left(593{ }^{\circ} \mathrm{C}\right.$ to $\left.585^{\circ} \mathrm{C}\right)$, indicating that the forced convection by intensive shearing restricted the growth of particles when they had grown to a certain size. This particle growth behavior may be related to the solid particles' coherency in the slurry, which is reported to be about $865 \mathrm{~K}\left(592{ }^{\circ} \mathrm{C}\right)$ for the AZ91 magnesium alloy under moderate shear rate, ${ }^{[34]}$ although more investigations are required to understand the mechanisms behind this phenomenon.

However, there was an increased nucleation rate during extrusion, resulting in a sudden increase in particle density, as shown in Figure 5(b). This could be caused by the increased cooling rate when the slurry was fed at $863 \mathrm{~K}\left(590{ }^{\circ} \mathrm{C}\right)$ into the barrel at a lower temperature. On average, the cooling rate in slurry making was $\sim 5^{\circ} \mathrm{C} / \mathrm{min}$ compared with $40{ }^{\circ} \mathrm{C} / \mathrm{min}$ to $140{ }^{\circ} \mathrm{C} / \mathrm{min}$ in the barrel during extrusion. Figures 11(a) and (b) show microstructures for the as-quenched slurry and as-extruded rod processed at the same temperature of $853 \mathrm{~K}\left(580{ }^{\circ} \mathrm{C}\right)$. It can be seen from the figure that after extrusion at $853 \mathrm{~K}$ $\left(580^{\circ} \mathrm{C}\right)$ there are newly formed primary phase particles and most of them are either dendritic or rosettelike. This 

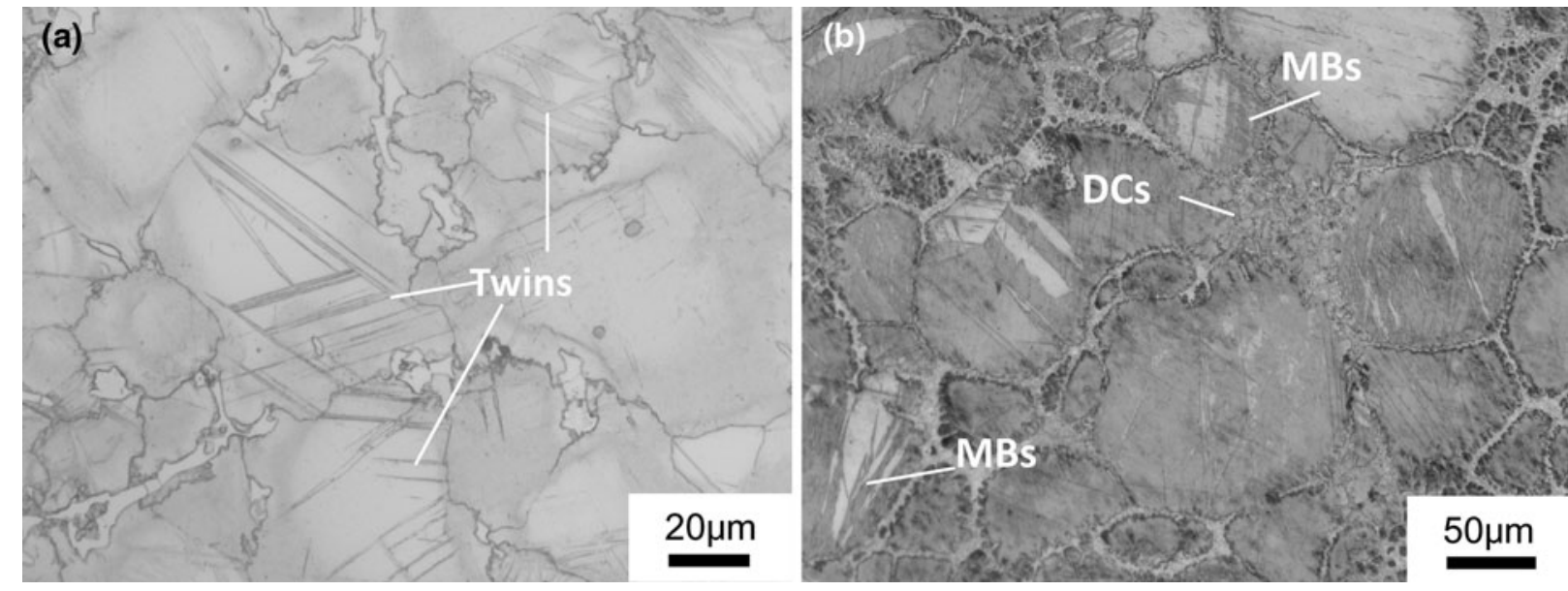

Fig. 8 - Optical micrographs of the extruded AZ91D rods, showing features of plastic deformation at extrusion temperatures of $(a) 833 \mathrm{~K}$ $\left(560^{\circ} \mathrm{C}\right)$ and $(b) 818 \mathrm{~K}\left(545^{\circ} \mathrm{C}\right)$.
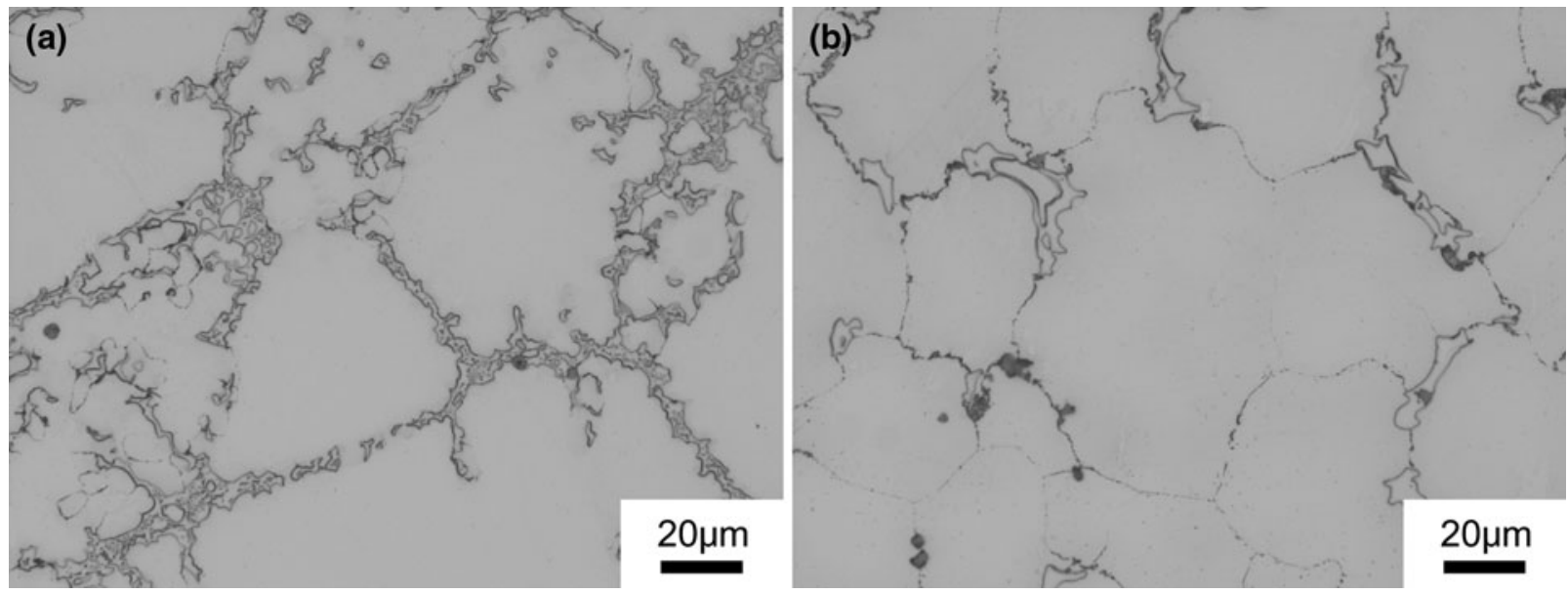

Fig. 9- Optical micrographs obtained slightly etched surfaces of extruded AZ91D samples, showing $(a)$ thick and continuous intermetallic networks extruded at $853 \mathrm{~K}\left(580{ }^{\circ} \mathrm{C}\right)$ and $(b)$ thin and broken ones at $818 \mathrm{~K}\left(545^{\circ} \mathrm{C}\right)$.

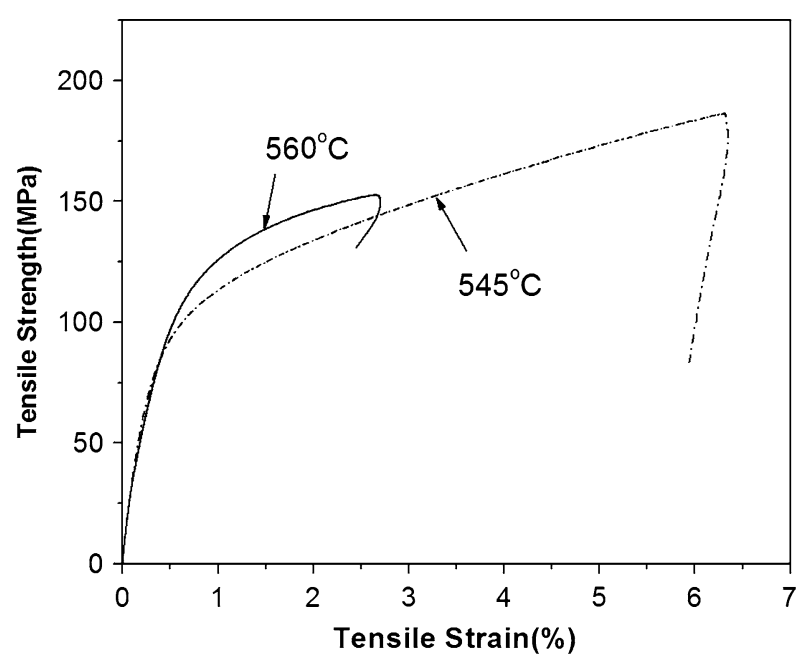

Fig. 10-Typical tensile stress-strain curves for the AZ91D samples extruded at $833 \mathrm{~K}$ and $818 \mathrm{~K}\left(560{ }^{\circ} \mathrm{C}\right.$ and $\left.545^{\circ} \mathrm{C}\right)$. strongly suggests that there was an increased nucleation rate when the slurry was transported in the barrel due to the temperature drop, although at $853 \mathrm{~K}\left(580^{\circ} \mathrm{C}\right)$, the shearing applied by the twin screws was probably not sufficient to provide a spherical growth condition. However, at lower extrusion temperatures, corresponding to increased solid fractions, the shearing in the barrel was adequate to transform the dendrites and rosettes into granular microstructures, as shown in Figure 11(c), which is a typical nondendritic microstructure obtained after extrusion at $833 \mathrm{~K}\left(560{ }^{\circ} \mathrm{C}\right)$. The increased solid fraction at lower temperatures resulted in higher slurry viscosity and higher shear resistance, and thus triggered a high shear stress to retain the same shear rate. This may explain the enhanced effect of shearing at lower extrusion temperature. On the other hand, low-temperature extrusion provides more driving force for particles to grow and a higher intensity of turbulence, leading to the development of a nondendritic structure under relatively low shear. The shear rate of the twin screw, corresponding to 

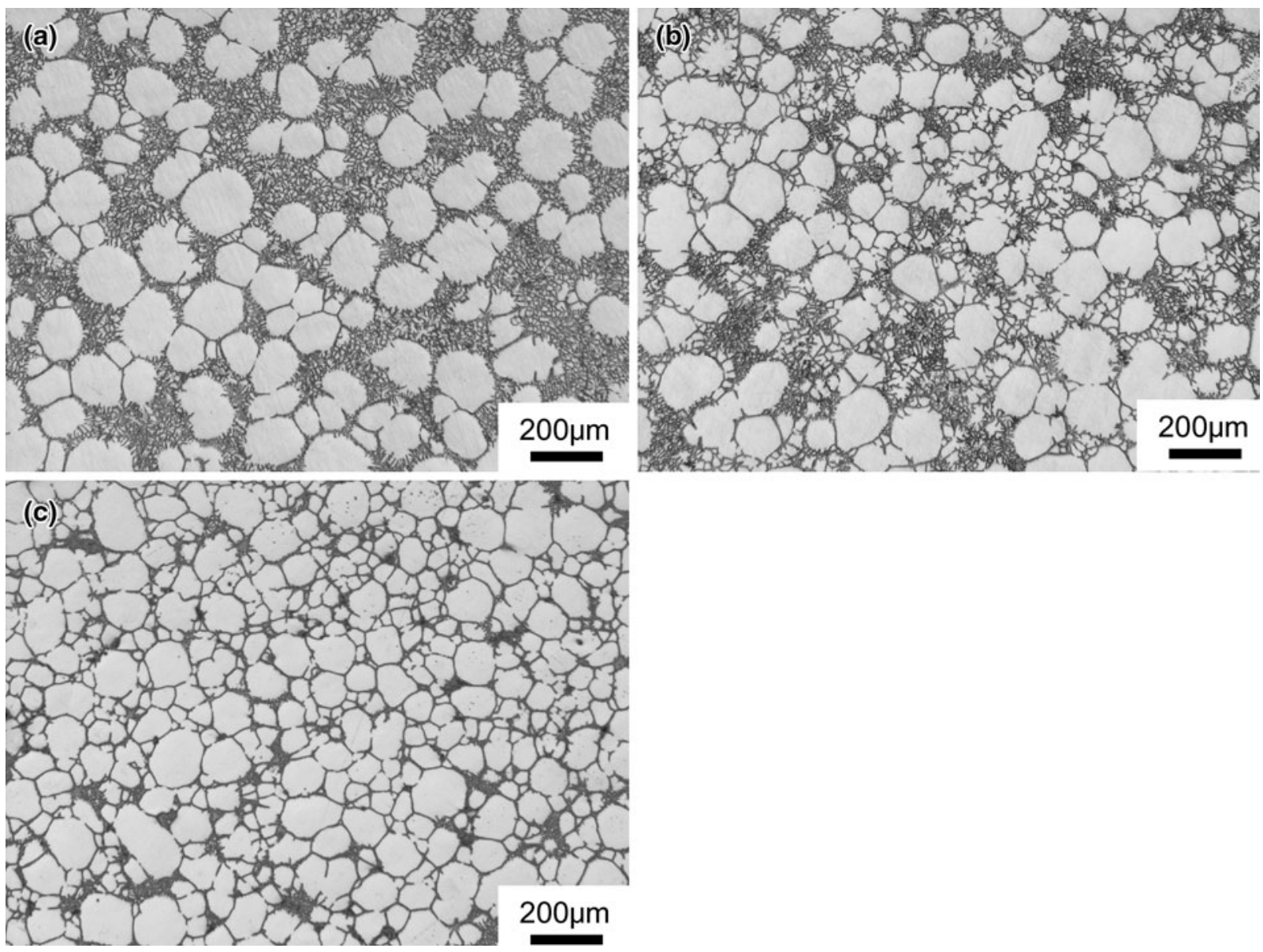

Fig. 11-Optical micrographs showing size, size distribution, and morphologies of primary phase particles for (a) the AZ91D slurry water quenched at $853 \mathrm{~K}\left(580^{\circ} \mathrm{C}\right)$ and $(b)$ an AZ91D rod extruded at $853 \mathrm{~K}\left(580^{\circ} \mathrm{C}\right)$ and $(c)$ at $560 \mathrm{deg}$.

a rotation speed of $150 \mathrm{rpm}$, was about $400 / \mathrm{s}$, and the present result is in agreement with the findings in an $\mathrm{Sn}-\mathrm{Pb}$ alloy by Ji and co-workers. ${ }^{[35]}$

\section{B. Microstructural Defects and Mechanical Properties}

Liquid segregation during feeding and extrusion was effectively avoided, and a fine and uniform microstructure was obtained at low extrusion temperatures, as shown in Figures 6 and 7. However, the eutectic structures or intermetallic networks formed during secondary solidification deteriorated to a certain extent the mechanical performance of the extruded rods. The secondary solidification of the remnant liquid took place during water quenching as the material was extruded out of the die assembly, forming a network of fine secondary $\alpha-\mathrm{Mg}$ grains together with $\beta-\mathrm{Mg}_{17} \mathrm{Al}_{12}$ intermetallics and a small amount of eutectic structures between $\alpha-\mathrm{Mg}$ and $\beta-\mathrm{Mg}_{17} \mathrm{Al}_{12}$ phases, in the matrix of primary $\alpha-\mathrm{Mg}$ granular grains, as shown in Figures 6 and 9. It has been claimed in the literature ${ }^{[17,21,36]}$ that both strength and ductility decrease with increasing solid fraction, corresponding to decreasing extrusion temperature in the present investigation. Czerwinski and co-workers ${ }^{[17]}$ blame the increased microchemical and microstructural heterogeneity, in the form of $\mathrm{Al}$ and $\mathrm{Zn}$ segregation, $\mathrm{Mg}_{17} \mathrm{Al}_{12}$ precipitates, and eutectic islands, for the decreased strength and ductility when primary solid content increases. However, in a thixomolding investigation, ${ }^{[21]}$ increasing solid fraction was found to have resulted in reduced tensile strength and ductility, whereas lowering the processing temperature apparently improved mechanical properties. These findings are contradictory and no explanations have been given. It was clear in the present work that mechanical performance of the extruded material was enhanced with decreasing extrusion temperature or increasing solid fraction. The reduced remnant liquid and grain size at low extrusion temperatures resulted in eutectic phases of lesser amount and improved distribution.

The grain structure obtained at $818 \mathrm{~K}\left(545^{\circ} \mathrm{C}\right)$ in this work is rather uniform and fine compared to a normal SSM forming process. However, it is still apparently coarser than those obtained by some thixomolding processes and solid-state extrusion. It is a major objective for the next step of the TSRE process development to refine the microstructure by further decreasing processing temperature and increasing shearing speed during extrusion. The effect of weak and brittle phases and microstructural defects on mechanical properties of magnesium alloys has been well addressed in the literature, ${ }^{[17,21,37]}$ and the mechanical behavior of 
the extruded material during tensile deformation will not be discussed in detail. Heat treatment to AZ91D components manufactured by rheo-casting was reported to effectively improve both microstructures and mechanical properties, ${ }^{[38]}$ and it is believed that postextrusion thermomechanical processing will improve the mechanical behavior of the extruded products, although more investigations are needed in this area.

\section{Thermal Management}

In order to maintain smooth and steady slurry feeding for the continuous TSRE process, the feeding temperature was set to be higher than the extrusion temperature. The process thus started from a transient state in which the slurry temperature decreased gradually while the barrel temperature increased before reaching a steady state. The steady-state extrusion temperature is estimated by simplified thermal analysis as follows.

For a given extrusion speed $(V)$ and a given slurry temperature drop $(\Delta T)$ from the feeding point to the entrance of the die assembly, the slurry heat loss rate during transport is

$$
\dot{Q}_{S}=\frac{1}{4} \pi \phi^{2} \rho V\left(C_{p} \Delta T-H \Delta f_{s}\right)
$$

where $\phi$ is the diameter of the extruded rod, $\rho$ the material density, $C_{p}$ the heat capacity of the material, $H$ the latent heat of fusion, and $\Delta f_{s}$ the solid fraction increase corresponding to the temperature drop $\Delta T$. The heat loss of the slurry during transport occurred by convection heat transfer between the slurry and the barrel internal surface, where the heat is conducted through the barrel wall. Because the heat convection coefficient between the slurry and the barrel internal surface $\left(\sim 3000 \mathrm{~W} / \mathrm{m}^{2} \mathrm{~K}\right)$ is substantially higher than the heat conductivity $\left(38 \mathrm{~W} / \mathrm{m}^{2} \mathrm{~K}\right)$ of the barrel wall, the temperature at the barrel internal surface is assumed to be equal to the slurry temperature $\left(T_{s}\right)$. The slurry temperature in the radian direction is uniform, and heat transfer along the axis direction only contributes to the temperature gradient change but not the slurry heat loss. Therefore, the overall heat transfer rate is only determined by the radial heat conduction through the barrel wall.

As shown in Figure 12, the twin screw geometry is simplified as a solid cylindrical column in the middle of the barrel. The diameter of the column is determined by the equivalent volume corresponding to the actual structure. The slurry then flows in-between the screw column and the barrel. Under the simplified geometry, the heat loss rate of the slurry by radial heat conduction through the barrel wall for a barrel segment $\Delta l\left(\Delta \dot{Q}_{B}\right)$ is given as

$$
\Delta \dot{Q}_{B}=2 \pi h_{b}(\Delta l) \frac{T_{s}-T_{b o}}{\ln \left(r_{o} / r_{i}\right)}
$$

where $T_{b o}$ is the temperature at the outside surface of the barrel, which is equal to the nominal extrusion temperature $\left(T_{e}\right) ; h_{b}$, the heat conductivity of the barrel; and $r_{i}$ and $r_{o}$, the inner radius and outer radius

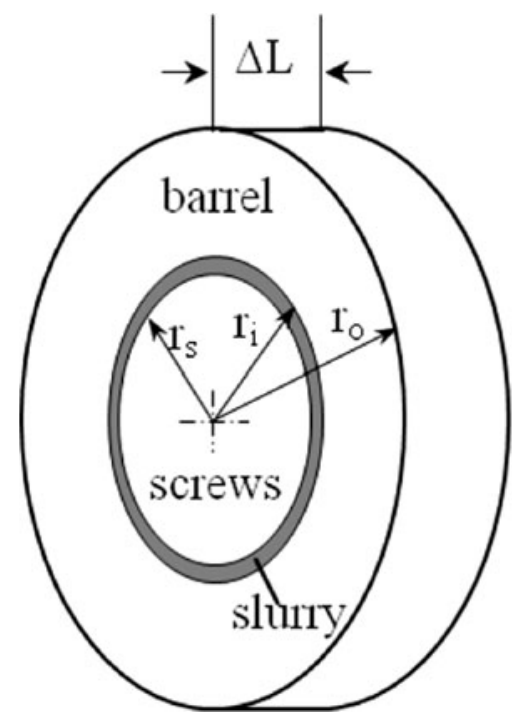

Fig. 12-Geometrical model for thermal analysis.

of the barrel, respectively. Assuming $T_{s}$ decreases linearly along the barrel, the integration of Eq. [5] over the full length of the barrel $(L)$ gives the total heat loss rate through the barrel wall $\left(\dot{Q}_{B}\right)$ as

$$
\dot{Q}_{B}=\pi h_{b} L \frac{2 T_{f}-2 T_{e}-\Delta T}{\ln \left(r_{o} / r_{i}\right)}
$$

where $\Delta T$ is the total slurry temperature drop in the barrel. At the steady state, $\dot{Q}_{S}=\dot{Q}_{B}$; then

$$
\Delta T=\frac{8 h_{b} L\left(T_{f}-T_{e}\right)}{4 h_{b} L+V \rho \phi^{2} \ln \left(r_{o} / r_{i}\right)\left(C_{p}+H / \Delta T_{f r}\right)}
$$

using an approximation $\Delta f_{s}=\Delta T / \Delta T_{f r}$, where $\Delta T_{f r}=$ $T_{L}-T_{S}$ is the freezing range of the alloy, where $T_{L}$ and $T_{S}$ are the liquidus and solidus of the material, respectively.

In the analysis, the slurry temperature is assumed to be uniform, which is reasonable as the gap for slurry flow is in the range of 0.5 to $2 \mathrm{~mm}$ and the constant shearing also helps to homogenize the slurry temperature. The effect of the screws on slurry temperature is important in the early stages, because the screws absorb a considerable amount of heat from the slurry. Their effect is negligible during the steady-state extrusion, because they have the same temperature as the slurry without sources of heat generation. The parameters used for analysis are given in Table I. Figure 13 shows the predicted extrusion temperature, $T_{P E}=T_{e}-\Delta T$, as a function of the nominal extrusion temperature $\left(T_{e}\right)$ at the extrusion speed of $10 \mathrm{~m} / \mathrm{min}$. It can be seen from the figure that for a given feeding temperature $\left(T_{f}\right), T_{P E}$ is proportional to $T_{e}$, as defined in Eq. [8]. The proportional constant is determined by the applied thermal condition (nominal extrusion temperature $T_{e}$ ), material parameters (density $\rho$, heat capacity $C_{p}$, and the latent heat of fusion $H$ ), extruder dimensions (barrel length $L$ and diameters $r_{i}$ and $r_{o}$ ), extrusion speed $V$, and the diameter of the extruded strand $(\phi)$. The analysis indicates that, for a given TSRE system and product to be processed, the actual 
Table I. Variables and Parameters Used in the Thermal Analysis

\begin{tabular}{|c|c|c|}
\hline Symbol & Value & Description (unit) \\
\hline$r_{o}$ & 0.050 & outer radius of the barrel $(\mathrm{m})$ \\
\hline$r_{i}$ & 0.028 & inner radius of the barrel (m) \\
\hline$r_{s}$ & 0.025 & equivalent radius of the twin screws (m) \\
\hline$h_{b}$ & 38 & $\begin{array}{l}\text { thermal conductivity of the barrel } \\
\left(\mathrm{W} \cdot \mathrm{m}^{-1} \cdot \mathrm{K}^{-1}\right)\end{array}$ \\
\hline$\rho$ & 1654.06 & density of the slurry $\left(\mathrm{kg} \cdot \mathrm{m}^{-3}\right)$ \\
\hline$C_{p}$ & 1183.25 & specific heat of slurry $\left(\mathrm{J} \cdot \mathrm{kg}^{-1} \cdot \mathrm{K}^{-1}\right)$ \\
\hline$H$ & 360,000 & latent heat of slurry, $\mathrm{J} \cdot \mathrm{kg}^{-1}$ \\
\hline$k$ & 0.36 & partition coefficient of the alloy \\
\hline$T_{f}$ & 590 & feeding temperature $\left({ }^{\circ} \mathrm{C}\right)$ \\
\hline$T_{L}$ & $\sim 598$ & liquidus of the alloy $\left({ }^{\circ} \mathrm{C}\right)$ \\
\hline$T_{S}$ & $\sim 470$ & solidus of the alloy $\left({ }^{\circ} \mathrm{C}\right)$ \\
\hline$T_{e}$ & 545 to 585 & nominal extrusion temperature $\left({ }^{\circ} \mathrm{C}\right)$ \\
\hline
\end{tabular}

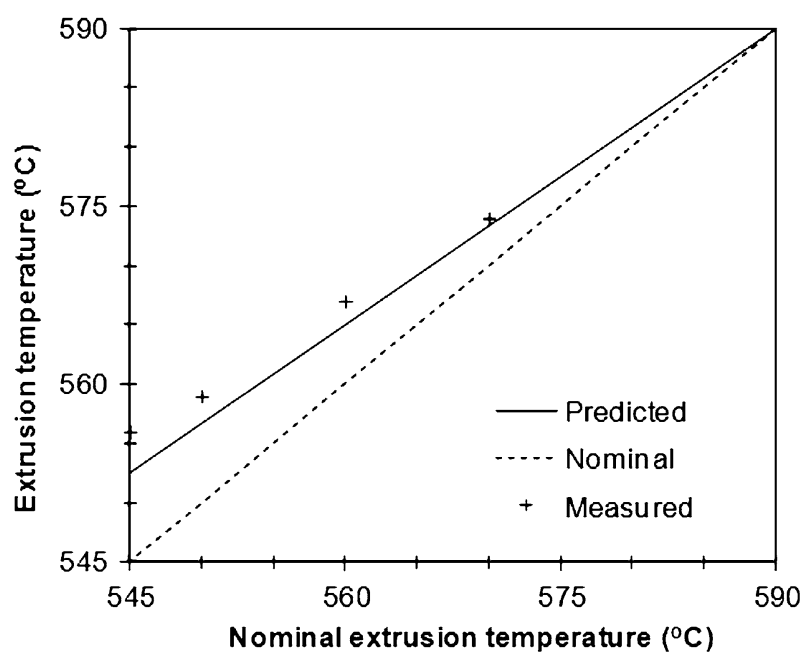

Fig. 13-Predicted extrusion temperature as a function of the nominal extrusion temperature in comparison with the measured extrusion temperature $(V=0.166 \mathrm{~m} / \mathrm{s}, \quad L=0.35 \mathrm{~m}, \phi=0.01 \mathrm{~m}$, $\left.T_{f}=863 \mathrm{~K}\left(590{ }^{\circ} \mathrm{C}\right)\right)$.

extrusion temperature can be manipulated by changing the thermal conditions of the barrel and extrusion speed. Also included in Figure 13 are the measured extrusion die temperatures $\left(T_{M E}\right)$ at the steady state, which are close to the analytically predicted $T_{P E}$.

Figure 14 shows the predicted extrusion temperature as a function of the barrel length and extrusion speed at various nominal extrusion temperatures. It can be seen that at a relatively low extrusion speed and long barrel size, the slurry can be cooled to the preset nominal extrusion temperature. The barrel length at which the slurry temperature is equal to the preset extrusion temperature $\left(L_{e}\right)$ is linearly related to the extrusion speed $(V)$ as

$$
L_{e}=\frac{\rho \phi^{2} \ln \left(r_{o} / r_{i}\right)\left(C_{p}+H / \Delta T_{f r}\right)}{4 h_{b}} V
$$

According to Eq. [8], the diameter of the extruded strand $(\phi)$ has higher power than all the other factors on the achievement of the preset extrusion temperature.

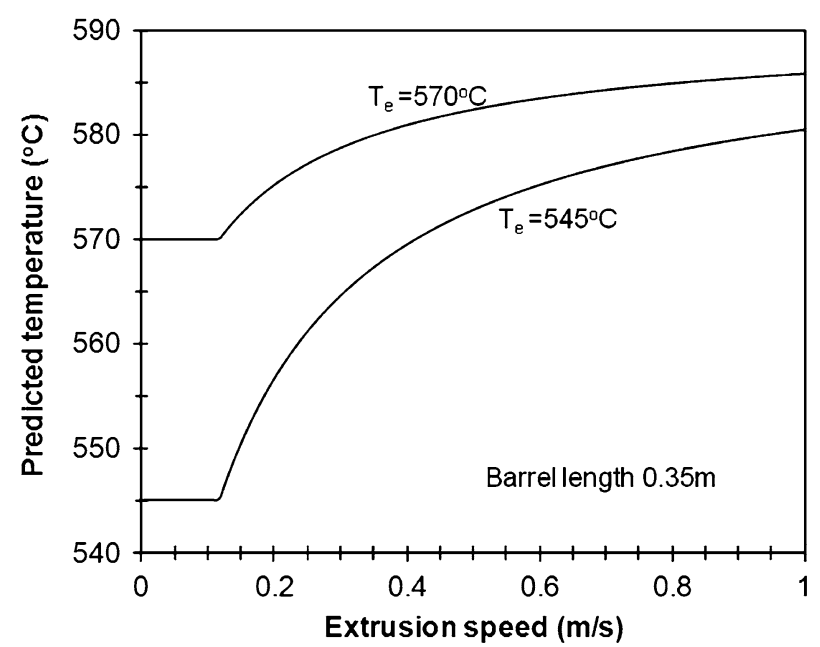

(a)

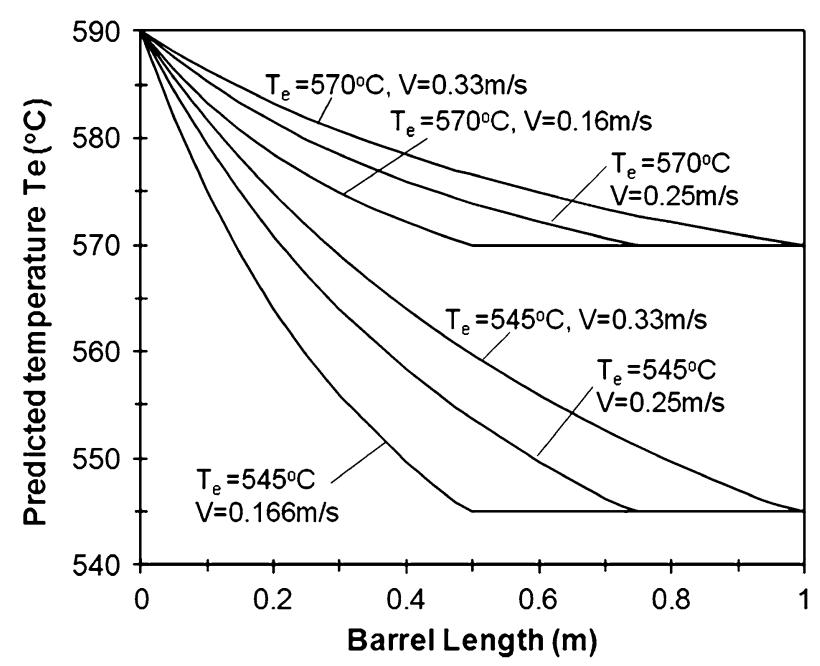

(b)

Fig. 14-Predicted extrusion temperature as a function of $(a)$ extrusion speed $\left(L=0.35 \mathrm{~m}, \phi=0.01 \mathrm{~m}, T_{f}=863 \mathrm{~K}\left(590{ }^{\circ} \mathrm{C}\right)\right)$ and $(b)$ barrel length at the preset extrusion temperatures of $818 \mathrm{~K}$ and $843 \mathrm{~K}\left(545^{\circ} \mathrm{C}\right.$ and $\left.570{ }^{\circ} \mathrm{C}\right)\left(\phi=0.01 \mathrm{~m}, T_{f}=863 \mathrm{~K}\left(590{ }^{\circ} \mathrm{C}\right)\right)$.

It is thus important to choose the right product size for the process thermal management.

The preceding analysis cannot predict the time required to establish the steady state, and more detailed and sophisticated analysis, taking into consideration the effect of temperature gradient along the barrel axis and precise thermal boundary conditions, is needed to obtain the information. It was expected that significant slurry temperature drop should occur within a very short period of time because of the heat absorption of the twin screws, which have a volume much larger than the slurry to be transported. Figure 15 is a record of the extrusion die temperature during an experiment at the preset extrusion temperature of $818 \mathrm{~K}\left(545^{\circ} \mathrm{C}\right)$, and it shows that significant temperature changes took place within the first 15 to 20 seconds, although a steady-state temperature required a longer time to be established. 


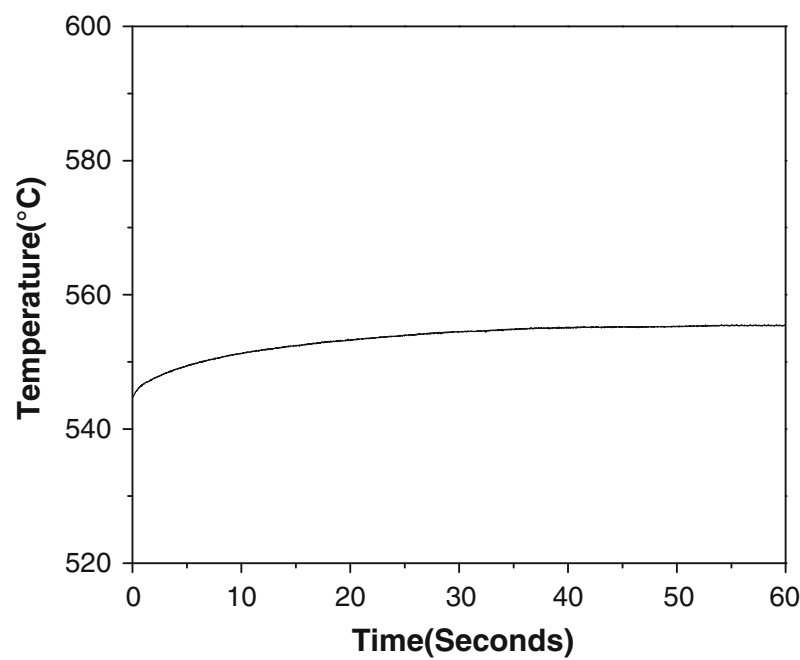

Fig. 15-Recorded temperature for the extrusion die as a function of time during the initial stages of TSRE for the AZ91D alloy. The preset extrusion temperature was $818 \mathrm{~K}\left(545^{\circ} \mathrm{C}\right)$; a steady-state temperature of $556{ }^{\circ} \mathrm{C}$ was reached after about $60 \mathrm{~s}$, although the temperature change occurred more rapidly in the first 15 to $20 \mathrm{~s}$.

\section{Technical Advantages of TSRE}

In addition to commercial benefits such as shortened production route, reduced manufacturing costs, and significant energy and materials savings, the continuous TSRE process with the current design also has several technical advantages. First, the in-situ slurry making by the novel online rotor-stator high shear device provides an essential and important condition for continuous semisolid processing, making the process more compact and efficient. Second, the use of twin screws as the driving means, the core of this process innovation, not only makes continuous processing a reality, but also offers a unique feature of forced convection by intensive shearing being applied during extrusion, therefore eliminating otherwise possible dendritic growth and liquid segregation. The shearing by the twin screws also helps develop a uniform field of temperature and chemistry and offers an additional measure in microstructure control by controlling convection intensity and mechanical impact to the slurry. Third, the adopted thermal scheme, in which the extruder is set to a lower temperature than that of the slurry at the feeding point and is used as an extended slurry maker, has several benefits. The scheme provides the slurry with high fluidity, allows a continuous and smooth material flow during transport in the barrel, and cuts down slurry preparation time, minimizing energy consumption for slurry making and extrusion. It also reduces processing time before forming and prohibits potential particle growth in a prolonged procedure. However, to allow slurry temperature changes during extrusion brings challenges for thermal management and accurate microstructural control, although these challenges proved to be manageable in the present laboratory scale experiments.

\section{CONCLUSIONS}

1. A TSRE process was developed. The process has several innovative features, including in-situ slurry making using a high shear rotor-stator and continuous processing by the employment of selfswept counter-rotating twin screws, offering a true one-step melt-to-product technology for metal production.

2. A feasibility study of the twin screws rheo-extrusion process was successfully carried out using a commercial magnesium alloy AZ91D. AZ91D rods with a fine and uniform microstructure and moderate mechanical properties were produced at a feeding temperature of $863 \mathrm{~K}\left(590{ }^{\circ} \mathrm{C}\right)$, extrusion temperature of $818 \mathrm{~K}\left(545{ }^{\circ} \mathrm{C}\right)$, and extrusion speed of $10 \mathrm{~m} / \mathrm{min}$.

3. The process has displayed advantageous features in microstructure control. The high shear rotor-stator can produce slurries of fine, uniform nondendritic primary phase particles. The nondendritic microstructure was maintained and refined due to further shear by the twin screws and plastic deformation during extrusion. Liquid segregation was avoided as intensive shearing was applied throughout the process.

4. The mechanical properties of the extruded rods are largely controlled by the microscale heterogeneities in structure and chemistry, namely, the size, morphology, and volume of the secondarily solidified phases and defects. At a fixed extrusion speed and slurry feeding temperature, lowering the extrusion temperature was shown to improve microstructure and tensile performance.

5. Experimental results and thermal analysis confirmed that a steady-state extrusion can be established in which the slurry temperature is managed to decrease during transportation in the extruder, allowing a sufficient solid fraction to be developed for forming.

\section{ACKNOWLEDGMENTS}

The authors express thanks to the EPSRC (UK) and Rautomead Ltd. for their financial support of this project.

\section{REFERENCES}

1. D.B. Spencer, R. Mehrabian, and M.C. Flemings: Metall. Trans., 1972, vol. 3, pp. 1925-32.

2. Z. Fan: Int. Mater. Rev., 2002, vol. 47, pp. 49-86.

3. Z. Fan: Mater. Sci. Eng. A, 2005, vols. 413-414, pp. 72-78.

4. S.-J. Liu, W.C. Keung, and Y.-L. Kang: Trans. Nonferrous Met. Soc. China, 2010, vol. 20, pp. 1805-14.

5. M.C. Flemings: Metall. Trans. A, 1991, vol. 22A, pp. 957-81.

6. R. Decker and R. Carnahan: Thixomolding, ASM Handbook, ASM, Materials Park, OH, 2008, vol. 15, pp. 777-79.

7. S.B. Brown and M.C. Flemings: Adv. Mater. Process., 199, vol. 143, pp. 36-40.

8. R. Song, Y. Kang, and A. Zhao: J. Mater. Process. Technol., 2008, vol. 198 , pp. 291-99.

9. E. Tzimas and A. Zavaliangos: J. Mater. Sci., 2000, vol. 35, pp. 5319-29.

10. K.P. Young, C.P. Kyonka, and J.A. Courtois: U.S. Patent 4,415,374, 1983 
11. L.E. Boyed, D.H. Kirkwood, and M.M. Sellars: Proc. 2nd World Basque Conf. on New Structural Materials, A.K. Bhasin, J.J. Moore, K.P. Young, and S. Midson, eds., Servico Central de Publicaciones del Gobierno Vasco, Madrid, 1988, pp. 285-95.

12. J. Wannasin, S. Janudom, T. Rattanochaikul, and R. Canyook: Trans. Nonferrous Met. Soc. China, 2010, vol. 20, pp. s1010s1015.

13. R. Nagata, Y. Uetani, H. Takagi, K. Matsuda, and S. Ikeno: Mater. Sci. Forum, 2006, vols. 519-521, pp. 1847-52.

14. H. Peng, S.P. Wang, N. Wang, and K.K. Wang: Proc. 3rd Int. Conf on Semisolid Processing of Alloys and Composites, M. Kiuchi, ed., Institute of Industrial Science, Tokyo, 1994, pp. 191-200.

15. S. Ji, Z. Fan, and M.J. Bevis: Mater. Sci. Eng. A, 2001, vol. 299A, pp. $210-17$.

16. X. Du and E. Zhang: Mater. Lett., 2007, vol. 61, pp. 2333-37.

17. F. Czerwinski, A. Zielinska, P.J. Pinet, and J. Overbeeke: Acta Mater., 2001, vol. 49, pp. 1225-35.

18. F. Czerwinski: Acta Mater., 2004, vol. 52, pp. 5057-69.

19. Z. Fan and G. Liu: Acta Mater., 2005, vol. 53, pp. 4345-57.

20. J.G. Wang, H.Q. Lin, H.Y. Wang, and Q.C. Jiang: J. Alloys Compd., 2008, vol. 466, pp. 98-105.

21. Y.F. Zhang, Y.B. Liu, Z.Y. Cao, Q.Q. Zhang, and L. Zhang: J. Mater. Process. Technol., 2009, vol. 209, pp. 1375-84.

22. R. Guan, J. Wen, S. Wang, and X. Liu: Trans. Nonferrous Met. Soc. China, 2006, vol. 16, pp. 382-86.

23. F. Czerwinski and A. Zielinska-Lipiec: Acta Mater., 2005, vol. 53, pp. 3433-44.

24. A. Vogel and B. Cantor: J. Cryst. Growth, 1977, vol. 37, pp. 309-16.
25. A. Hellawell: Proc. 4th Int. Conf. on Semi-Solid Processing of Alloys and Composites, D.H. Kirkwood and P. Kapranos, eds., Sheffield, United Kingdom, 1996, pp. 60-66.

26. R.D. Doherty, H.-I. Lee, and E.A. Feest: Mater. Sci. Eng. A, 1984, vol. 65A, pp. 181-89.

27. J.M.M. Molenaar, F.W.H.C. Salemans, and L. Katgerman: J. Mater. Sci., 1985, vol. 20, pp. 4335-42.

28. J.M.M. Molenaar, L. Katgerman, W.H. Kool, and R.J. Smeulders: J. Mater. Sci., 1986, vol. 21, pp. 389-97.

29. A.M. Mullis: Acta Mater., 1999, vol. 47, pp. 1783-82.

30. S. Ji and Z. Fan: Metall. Mater. Trans. A, 2002, vol. 33A, pp. 3511-20.

31. A. Das, S. Ji, and Z. Fan: Acta Mater., 2002, vol. 50, pp. 4571-85.

32. R.S. Qin and E.R. Wallach: Mater. Sci. Eng. A, 2003, vol. 357A, pp. $45-54$.

33. H. Men, B. Jiang, and Z. Fan: Acta Mater., 2010, vol. 58, pp. $6526-34$

34. C.M. Gourlay, B. Meylan, and A.K. Dahle: Acta Mater., 2008, vol. 56 , pp. 3403-13.

35. S. Ji, A. Das, and Z. Fan: Scripta Mater., 2002, vol. 46, pp. 205-10.

36. D. Ghosh, K. Kang, C. Bach, J.G. Roemer, and C. Vanschilt: Proc. Int. Symp. on Recent Metallurgical Advances in Light Metals Industries, S. Vancouver, BC, Canada, 1995, Macewen and J.P. Gilardeau, eds., Canadian Institute of Mining, Metallurgy and Petroleum, Cop., Montreal, QC, 1995, pp. 473-79.

37. L. Yang, Y. Kang, F. Zhang, and J. Xu: Trans. Nonferrous Met. Soc. China, 2010, vol. 20, pp. s863-s867.

38. Y. Wang, G. Liu, and Z. Fan: Acta Mater., 2006, vol. 54, pp. 689-99. 